\title{
La enseñanza y aprendizaje en Historia Antigua de Asia Oriental. Construyendo nuevas estrategias de innovación docente
}

\section{Teaching and Learning in Ancient History of East Asia. The Making of New Teaching Innovation Strategies}

JESÚS SAN-BERNARDINO CORONIL

ORCID: https://orcid.org/0000-0002-6400-2983

Universidad de Sevilla

Departamento de Historia Antigua

jcoronil@us.es

Fecha de recepción: 20/11/2019

Fecha de aceptación: /29/11/2019

DOI: http://dx.doi.org/10.12795/9788447221912.116

Pp.: 2572-2598 


\section{Resumen}

El artículo expone el diseño, aplicación y resultados de un ciclo de mejora en el aula (CIMA) centrado en la Historia Antigua de Asia Oriental (3 créditos) en el marco de una asignatura más genérica de "Historia Premoderna de Asia Oriental" (6 créditos) perteneciente al "Grado de Estudios de Asia Oriental" (Universidad de Sevilla). Se insiste en las estrategias para enseñar procesos históricos fundamentales pero complejos como la aparición de la escritura o la construcción del Estado en la China Antigua.

Palabras claves: Antigüedad, China, Historia, CIMA, docencia universitaria.

\section{Abstract}

The article exposes the design, application and results of a classroom improvement cycle (CIMA) focused on the "Ancient History of East Asia" (3 credits) within the framework of a more generic subject of "Premodern History of East Asia" (6 credits) belonging to the "Degree of East Asian Studies" (University of Seville). The strategies to teach fundamental but complex historical processes such as the appearance of writing or the construction of the State in Ancient China are insisted.

Keywords: Antiquity, China, History, CIMA, University Teaching.

Jornadas de Formación e Innovación Docente del Profesorado | № 2 (2019)

Esta obra se distribuye con la licencia Creative Commons 


\section{Descripción de las clases habituales, el modelo ideal y el posible.}

En este noveno curso consecutivo en el que vengo impartiendo la asignatura Historia Premoderna de Asia Oriental, asignatura del módulo de formación básica de 1음 curso del Grado en Estudios de Asia Oriental, he aplicado un ciclo de 30 horas totales (correspondientes al "área de conocimiento de Historia Antigua” con 3 créditos).

Esta asignatura ya ha sido objeto de mejoras de innovación docente en el curso pasado 2018-2029. En los 2 temas adaptados hasta el momento, se han modificado contenidos y adaptado estrategias docentes que parten de la importancia "de los modelos previos de aprendizaje de los alumnos" dado que los estudiantes no son una página en blanco. Lógicamente estas experiencias han influido en el modo de afrontar la asignatura en su conjunto. El temario de la asignatura cuenta con 7 unidades temáticas de extensión variable que se imparten en 15 semanas de clases.

El modelo habitual ha sido superado, en los sucesivos CIMA del curso de innovación docente impartido el pasado curso 2018-2919. Partiendo de la convicción de la importancia de los modelos de conocimientos previos de los alumnos para el aprendizaje de la perspectiva histórica para un área tan lejana del alumnado como Asia Oriental. Se trata de una triple lejanía: lejanía de conocimientos (dado que prácticamente carecen de ningún conocimiento previo porque la Historia de China, Japón y Corea no se imparte en la Educación Secundaria), lejanía geográfica (Asia Oriental se encuentra en el extremo oriental de Eurasia mientras que España se encuentra en el otro extremo, el Extremo Occidente de Eurasia) y de una lejanía cultural (Asia Oriental se encuentra en una esfera cultural que no solo no se basa en la civilización cristiana y grecorromana sino que ni siquiera comparte el mundo cultural de

Jornadas de Formación e Innovación Docente del Profesorado | № 2 (2019)

Esta obra se distribuye con la licencia Creative Commons 
las denominadas "Tres Culturas" del monoteísmo abrahámico -judaísmo, cristianismo e isla, salvo en algunas regiones de China). Salvar esa triple distancia es el pilar que da sentido a los debates, la participación y la observación en el aula.

Este año, el grupo de alumnos matriculados en la asignatura son aproximadamente 60-70 estudiantes. De ellos, 2 proceden de las becas de intercambio con Universidades de Asia Oriental (2 estudiantes de universidades japonesas). Los autóctonos suelen proceder de prácticamente todas las comunidades autónomas dado que este Grado en Estudios de Asia Oriental se imparte en no más de 10 universidades para el conjunto de toda España.

Respecto a los conocimientos previos del grupo, hemos testado sus intereses al matricularse en la asignatura, y a la vez que se ha "pulsado" esta realidad se ha aprovechado para impartir la unidad temática 1 sobre "Introducción a la historia pre-moderna de Asia Oriental" dado que este tema aborda los conceptos previos que se manejan y los "pre-juicios" o estereotipos a la hora de abordar la historia de Asia Oriental.

El método en que se basa la "impartición" de las diferentes unidades temáticas se centra en el aprendizaje en base a resolución de problemas (ARP) que resulta un método muy apropiado para una disciplina que se enfrenta a la investigación sobre el pasado como la Historia (Bain 2007: 33-59).

\section{Modelo ideal}

Nuestro modelo ideal se basa y corresponde con el modelo basado en el principio de investigación (Porlan, 2017: 45-49). Consta de varias etapas:

Jornadas de Formación e Innovación Docente del Profesorado | № 2 (2019)

Esta obra se distribuye con la licencia Creative Commons

Reconocimiento-NoComercial-SinObraDerivada $\quad 4.0$ Internacional (CC BY-NC-ND 4.0.) 
Paso 1. Planteamiento de una pregunta en clase para cada unidad temática (por ejemplo: ¿cómo se pasa de las sociedades de cazadores y recolectores a las sociedades campesinas en China?).

Paso 2: Se abre un turno de palabras en el aula. Durante esa sesión los alumnos intervienen a partir de sus conocimientos previos.

Paso 3: En la siguiente sesión, se observa si algunos de los estudiantes se han preocupado por informarse y si sus intervenciones son más elaboradas.

Paso 4: A partir de ahí, se señalan las incongruencias de ciertos planteamientos y se presenta información adicional (información de contraste).

Paso 5: Se procede a una recapitulación de ideas a modo de conclusiones.

Paso 6: Finalmente, se interpela directamente a todos y cada de los alumnos/as sobre qué considera que ha aprendido desde que planteara la pregunta inicial (cada alumno/a debe compartir con la clase al menos una idea-fuerza).

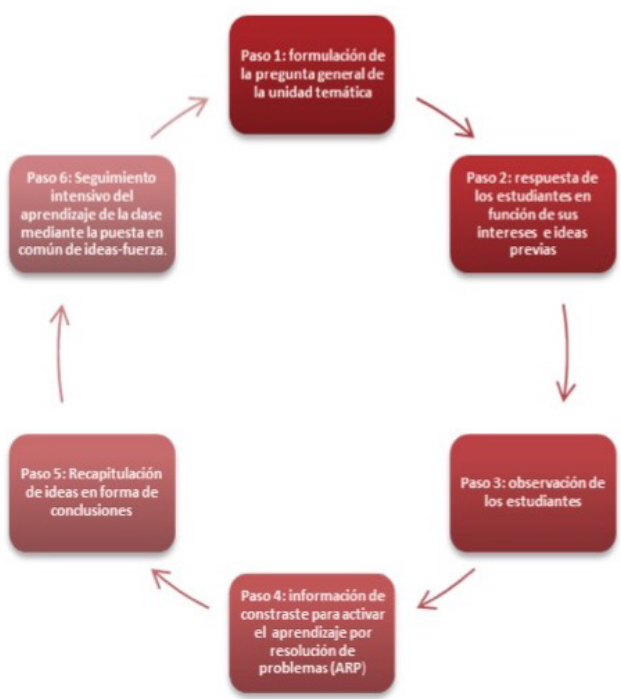

Figura 1: Modelo ideal

Jornadas de Formación e Innovación Docente del Profesorado | № 2 (2019)

Esta obra se distribuye con la licencia Creative Commons 
Sin embargo este modelo ideal en la práctica no resulta posible. $Y$ no resulta posible por tres razones fundamentales:

- el número de alumnos: 65 estudiantes matriculados en el presente curso son demasiados para estrategias individualizadas basadas en la resolución de problemas. - en la falta del tiempo de docencia: solo 3 créditos para explicar 5000 años de Historia de Asia Oriental en la Antigüedad no permite realizar milagros. Y las clases tipo ARP exigen mucho más tiempo en su desarrollo y aplicación práctica que las clases al uso (en el que se transmiten el conocimiento en clases magistrales en un contexto pasiva del estudiante, y se pasan al tema siguiente). Por otra parte, se nos exige que se imparta el temario en su totalidad con lo cual tienes que "correr" para impartir todos los temas (lo cual impide que como docentes podamos además disfrutar de transmitirlos y genera frustración).

En los temas seleccionados para desarrollar este proyecto de CIMA basado en "aprendizaje por resolución de problemas", hemos planteado el siguiente proceso como modelo posible:

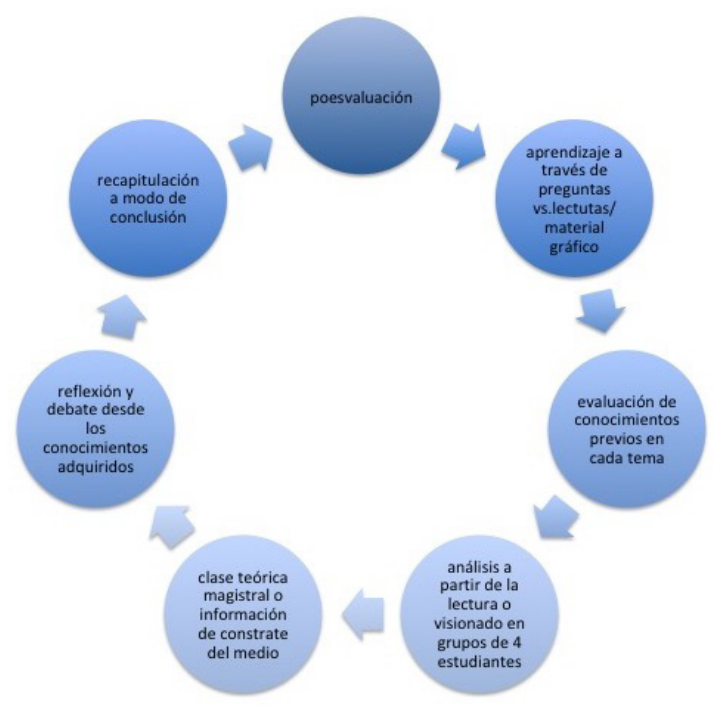

Figura 2: Modelo posible

Jornadas de Formación e Innovación Docente del Profesorado | № 2 (2019)

Esta obra se distribuye con la licencia Creative Commons 


\section{Modelo posible}

Este modelo basado en "aprendizaje por resolución del problemas" se fundamenta en la formulación de preguntas por cada unidad temática que lleva aparejado un contenido teórico-práctico que se adquiere a través de una lectura breve o visionado de material gráfico (diapositivas, power point, documentales).

Se requiere evaluar los conocimientos previos de los alumnos sobre cada unidad temática.

A partir de ahí, se procede a la organización de grupos de $4 / 5$ estudiantes que deben contestar a un pequeño formulario de 3 a 5 preguntas aproximadamente. El grupo debe discutir las respuestas y acordarlas, a partir de la información extraída en la lectura o visionado del material gráfico.

Tras la recogida de los cuestionarios tiene lugar una puesta en común que se recoge en la pizarra. De esta forma se plasma en un esquema en la pizarra cuál ha sido la respuesta general de la clase por cada una de las preguntas: con este procedimiento se han obtenido así 405 "pantallazos" sobre las respuesta dadas por los estudiantes a cada uno de los problemas fundamentales.

A continuación, el profesor ofrece información de contraste que puede consistir en comentarios o matizaciones sobre las respuestas ofrecidas en la clase o bien en una clase magistral de forma más estructurada.

En el siguiente paso se abre un debate para reflexionar sobre los conocimientos adquiridos a través de todos los pasos anteriores. El objetivo consiste en establecer feedback entre el conocimiento emitido por los alumnos, el conocimiento del profesor y el conocimiento construido conjuntamente en la puesta en común, en la reflexión y

Jornadas de Formación e Innovación Docente del Profesorado | № 2 (2019)

Esta obra se distribuye con la licencia Creative Commons 
en la recapitulación. Para ello, se cuenta con sesiones de 2 horas en la que se trata de cumplimentar todo el ciclo de aprendizaje.

Este modelo se ha puesto en práctica articulando todas las unidades temáticas del temario de la asignatura, como práctica de innovación para este curso 2019/20.

El modelo ha contado además con la participación observante de un par también aplicando en un CIMA en el Grado en Estudios de Asia Oriental: la profesora Ángeles Castaño Madroñal. Esta observación entre pares en una sesión de clases se ha introducido como innovación para este curso académico 2019-2020. Esta observación se ha recogido en un diario de la sesión, de modo que ha permitido compartir posteriormente las impresiones mutuas y realizar un análisis de la docencia desarrollada, para realizar posibles mejoras. La observación se ha realizado a mitad del CIMA (en la sesión de las 15-16 horas o en la sesión de las 17-18), de modo que ha dado tiempo de impartir y hacer rodaje con esta metodología y, a su vez, queda tiempo para introducir las mejoras o modulaciones en el calendario restante del curso académico.

\section{Elaboración del mapa de contenidos del CIMA}

Para el ejercicio de este curso, me he planteado el desarrollo del temario reagrupando temas en 7 unidades temáticas. La actividad de este año reestructura el temario para hacerlo más funcional y adaptable para la realización del CIMA (Porlán: 55-72).

1. Unidad temática 1. Introducción a la historia pre-moderna de Asia Oriental.

1.1. Espacio y tiempo: realidades geográficas y cronológicas de Asia Oriental.

1.2. Historiografias sobre Asia Oriental.

Jornadas de Formación e Innovación Docente del Profesorado I № 2 (2019)

Esta obra se distribuye con la licencia Creative Commons 
2. Unidad temática 2: Introducción a la historia de China: geografia, cronología e historiografia.

3. Unidad temática 3. Los orígenes de la historia en China. Del Paleolítico al Neolítico.

4. Unidad temática 4. La constitución de la historia china. Dinastías Xia, Shang y Zhou.

5. Unidad temática 5. La unificación de China en la Antigüedad. Dinastías Qin y Han.

6. Unidad temática 6. Corea Antigua.

7. Unidad temática 7. Japón Antiguo.

\section{Mapa de contenidos}

En la ilustración destaco los conceptos y contenidos claves de los temas que incluyen contenidos tanto conceptuales (en azul), actitudinales (en rojo) y procedimentales (en verde) En rojo he colocado las capacidades actitudinales generales de la asignatura a través del proyecto, y en verde las procedimentales generales de la asignatura y específicas e intelectuales del proyecto. El trabajo de la profesora Ángeles Castaño Madroñal (Castaño, 2018: 1817) ha resultado muy inspirador, por su claridad conceptual a la hora de diseñar el mapa de contenidos que aquí se presenta para esta asignatura.

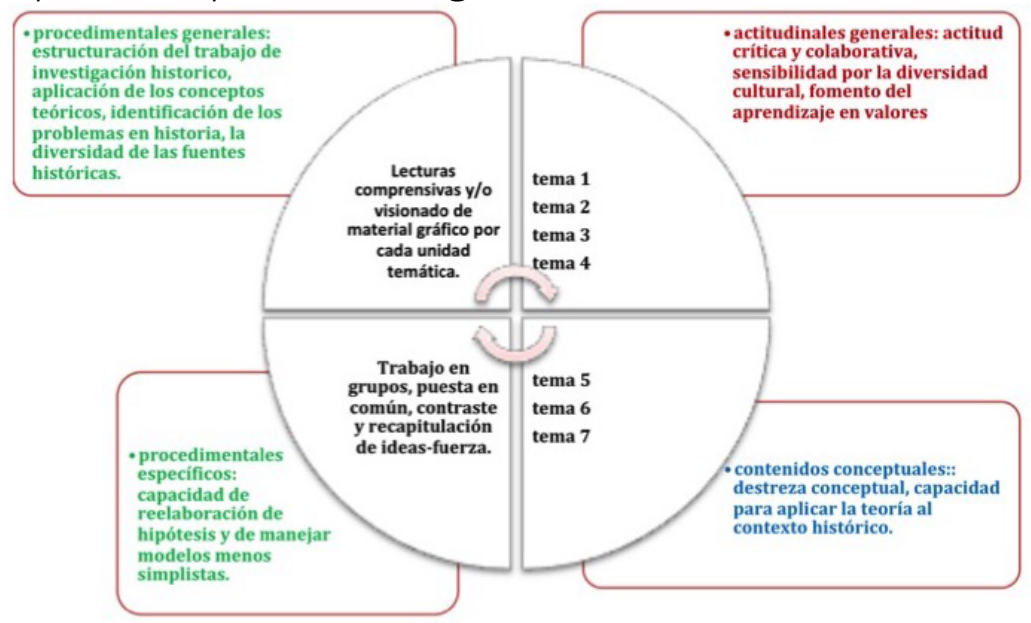

Figura 3: Mapa conceptual

Jornadas de Formación e Innovación Docente del Profesorado | № 2 (2019)

Esta obra se distribuye con la licencia Creative Commons 
Tabla 1. Preguntas Claves de Evaluación

\begin{tabular}{|c|c|}
\hline Presentación/ & Preguntas claves \\
\hline & $\begin{array}{l}\text { - ¿Cuál es tu nombre y apellidos? } \\
\text { - ¿Qué mención cursas, China o Japón? } \\
\text { - ¿Por qué elegiste este Grado (Grado en Estudios de Asia Oriental)? } \\
\text { - ¿Qué esperas aprender en este Grado? } \\
\text { - ¿A qué te gustaría dedicarte profesionalmente? }\end{array}$ \\
\hline PROYECTO & $\begin{array}{l}\text { *Identificación de los preconceptos y prejuicios de los estudiantes. } \\
\text { * Reflexión colectiva sobre "nuestros" pre-juicios sobre China, } \\
\text { Japón y Corea desde el mundo occidental de matriz grecorromana y } \\
\text { judeo-cristiana. }\end{array}$ \\
\hline \multirow[t]{2}{*}{ Tema 2} & Preguntas claves \\
\hline & $\begin{array}{l}\text { - ¿Qué caracteriza la geografía de China? } \\
\text { - ¿Cómo afectó esta geografía al desarrollo histórico? } \\
\text { - ¿Cómo se divide cronológicamente la historia de China? } \\
\text { - ¿Qué se piensa en Occidente sobre la historia de China? }\end{array}$ \\
\hline PROYECTO & $\begin{array}{l}\text { * Puesta en común a partir de la información de contraste ofrecida por el } \\
\text { profesor (en este caso, no recurriremos a artículos o material gráfico por } \\
\text { tratarse de un tema que va de cuestiones muy específicas y concretas } \\
\text { (por ejemplos, los ríos de China) a cuestiones muy conceptuales (cómo } \\
\text { se ha modelizado la historia de China como un ejemplo perfecto de } \\
\text { "despotismo oriental" en Occidente) }\end{array}$ \\
\hline \multirow[t]{2}{*}{ Tema 3} & Preguntas claves \\
\hline & $\begin{array}{l}\text { - ¿Qué papel jugaron los grandes ríos en las primeras culturas chinas? } \\
\text { - ¿Cómo se pasó de sociedades de cazadores y recolectores a socie- } \\
\text { dades de campesino? } \\
\text { - ¿Qué culturas neolíticas de China conoces? Cita al menos tres } \\
\text { - ¿Qué relación existe entre el neolítico y el mito del Gran Yu? } \\
\end{array}$ \\
\hline PROYECTO & $\begin{array}{l}\text { * Trabajo en equipo a partir de lecturas y material gráfico sobre las } \\
\text { preguntas claves. Estas preguntas claves se desmenuzaran en preguntas } \\
\text { más específicas relacionadas directamente con las lecturas (que } \\
\text { se extraerán fundamentalmente de artículos en pdf de la revista del } \\
\text { "Instituto Confucio" por estar en red y por tener una calidad de alta } \\
\text { divulgación). }\end{array}$ \\
\hline Tema 4 & Preguntas claves \\
\hline
\end{tabular}

Jornadas de Formación e Innovación Docente del Profesorado | № 2 (2019)

Esta obra se distribuye con la licencia Creative Commons

Reconocimiento-NoComercial-SinObraDerivada $\quad 4.0$ Internacional (CC BY-NC-ND 4.0.) 


\begin{tabular}{|c|c|}
\hline & $\begin{array}{l}\text { - ¿Cuál es la primera dinastía de China y con qué cultura arqueoló- } \\
\text { gica se vincula? } \\
\text { ¿Cuál es la segunda dinastía de China y qué conocemos arqueo- } \\
\text { lógicamente? ¿Qué relación guarda con la aparición del Estado en } \\
\text { China? ¿Qué ideología justifica el monopolio del poder en dicha es- } \\
\text { tructura estatal? } \\
\text { - ¿Cuál es la tercera dinastía de China? ¿Qué cambios en la ideología } \\
\text { justifica el monopolio del poder por la nueva dinastía? ¿Cómo se } \\
\text { denomina en China a dicha teoría? }\end{array}$ \\
\hline PROYECTO & $\begin{array}{l}\text { * Lectura de artículo en grupos de } 4 \text { estudiantes. Visionado de } \\
\text { documentales. Puesta en común crítica y recapitulación. }\end{array}$ \\
\hline \multirow[t]{2}{*}{ Tema 5} & Preguntas claves \\
\hline & $\begin{array}{l}\text { - ¿Cómo se explica la fragmentación del poder estatal en China al ini- } \\
\text { cio del período? } \\
\text { - ¿En cuántas etapas se divide el proceso de unificación de China? } \\
\text { - ¿Qué factores jugaron a favor del reino de Qin? } \\
\text { - ¿Qué reformas aplicó el primer emperador para consolidar la unifi- } \\
\text { cación del Estado? } \\
\text { - ¿Que caracteriza la evolución de China durante la dinastía Han? }\end{array}$ \\
\hline PROYECTO & $\begin{array}{l}\text { Información de contraste ofrecida por el docente tanto de carácter } \\
\text { teórico como gráfico por tratarse de un contenido muy específico sobre } \\
\text { el que los alumnos carecen de conocimientos previos. Se formularan no } \\
\text { obstante las preguntas para estimular la reflexión de los estudiantes. }\end{array}$ \\
\hline \multirow[t]{2}{*}{ Tema 6} & Preguntas claves \\
\hline & $\begin{array}{l}\text { - ¿Qué caracteriza el paso del Paleolítico al Neolítico en Corea? } \\
\text { - ¿Qué estados se pueden identificar en la Corea Antigua? }\end{array}$ \\
\hline \multirow[t]{2}{*}{ Tema 7} & Preguntas claves \\
\hline & $\begin{array}{l}\text { - ¿Qué caracteriza la prehistoria de Japón? } \\
\text { - ¿Qué papel juega la cerámica en la periodización y evolución histó- } \\
\text { rica de Japón en estos momentos? } \\
\text { - ¿Cómo aparece la agricultura en Japón? } \\
\text { - ¿Cómo se llama el último período histórico de Japón en esta fase y } \\
\text { que relación guarda con la aparición del Estado en Japón? }\end{array}$ \\
\hline PROYECTO & $\begin{array}{l}\text { * Contaremos con la conferencia de un arqueólogo especializado en su } \\
\text { tesis doctoral en la Prehistoria de Japón (con } 8 \text { campañas arqueológicas } \\
\text { in situ): Prof. Dr. Rafael Abad de los Santos. }\end{array}$ \\
\hline EVALUACIÓN & $\begin{array}{l}\text { AUTOEVALUACIÓN DEL ALUMNO/ EVALUACIÓN DE LA DOCENCIA/ } \\
\text { EVALUACIÓN DEL APRENDIZAJE }\end{array}$ \\
\hline
\end{tabular}

\section{Secuencia de actividades}

Para llevar a cabo este CIMA se ha establecido una secuencia de trabajo en el aula de 15 semanas con 4 horas de clase semanales basado en la preeminencia del

Jornadas de Formación e Innovación Docente del Profesorado | № 2 (2019)

Esta obra se distribuye con la licencia Creative Commons

Reconocimiento-NoComercial-SinObraDerivada $\quad 4.0$ Internacional (CC BY-NC-ND 4.0.) 
aprendizaje práctico y aplicado basado en la resolución de problemas con la siguiente clase tipo de forma general basado en el método ARP. Se trataría de sesiones de 2 horas repartidas en: 20' preevaluación; 40' análisis aplicado participativo a partir de lecturas y/o material gráfico en grupos de 4/5 estudiantes; 60' puesta en común mediante tormenta de ideas, información de contraste y recapitulación.

\section{Articulación entre el mapa de contenidos y el proyecto de innovación}

En la siguiente ilustración siendo la flecha el proyecto de innovación docente en su desarrollo cronológico a lo largo del trabajo en el aula durante 30 horas hasta mediados de noviembre (3 créditos), se refleja la secuencia de contenidos y temas entre los bloques temáticos. El proyecto establece un vínculo aplicado de todo el temario.

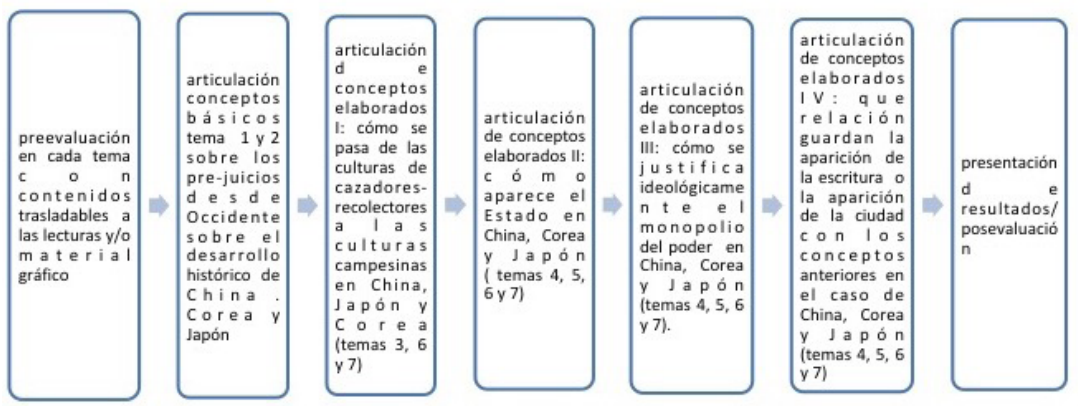

Figura 4. Mapa de contenidos.

\section{Evaluación de la dinámica de la clase.}

\section{Diario de clases}

A lo largo del CIMA se ha llevado registro en un diario de clases con anotaciones relativas a la práctica concreta y desarrollo de las sesiones en las que se ha recogido las

Jornadas de Formación e Innovación Docente del Profesorado | № 2 (2019)

Esta obra se distribuye con la licencia Creative Commons 
observaciones del día a día de la docencia y el proceso aprendizaje del grupo de estudiantes.

Durante las dos primeras sesiones los estudiantes se presentaron de acuerdo con sus motivaciones e inquietudes a la hora de iniciar sus estudios en el grado en estudios de Asia Oriental. Tras estas presentaciones el profesor ofreció información acerca de los estereotipos y prejuicios existentes en occidente sobre China, Japón y Corea. Y se emitió un cortometraje documental sobre esta problemática titulado Chino, Capuchino. Cómo los estereotipos afectan a los españoles (editado y producido por Ita Tsai, 2019 enlace en línea: https://www.youtube.com/watch?v=AmosZxePEZo). Se da la característica de que el estudiantado que cursa este grado es fuertemente vocacional y admirador de la cultura de Asia Oriental. Tras la proyección de video se inició un turno de palabras en el aula y curiosamente un número significativo de alumnos reconocía sorprendidos que dichos estereotipos anidaban en su interior: gracias a la información de contraste y a su reflexión ahora se percataban de manera consciente de la interiorización de dichos estereotipos. De hecho así lo expresan los propios sujetos en el cuestionario final de evaluación. De esta forma gracias a las sesiones de presentación y los debates resultantes quedó impartido el tema 1.

Las siguientes sesiones se dedicaron al tema 2 centrado en la geografia que de acuerdo con nuestro proyecto se explicó a partir de la información de contraste ofrecida por el docente con abundante material gráfico. Destaca particularmente el debate que se suscitó en el aula a partir de una diapositiva que señala que la mayor parte de la población mundial vive dentro de un círculo que abarca Asia Oriental, Asia Meridional y Sudeste Asiático (figura 1). Este dato sorprendió fuertemente a los alumnos pues significaría que la mayor parte de la humanidad reside en esa

Jornadas de Formación e Innovación Docente del Profesorado | № 2 (2019)

Esta obra se distribuye con la licencia Creative Commons 
macro región y que sin embargo apenas conocen nada de su historia, de su filosofia, de su arte, de su literatura etc...

Es decir que no conocían la filosofia, arte, literatura etc... de la mayor parte de la Humanidad. Se generó por tanto un debate acerca del eurocentrismo que afecta a la enseñanza secundaria centrada casi exclusivamente en Occidente: se produce así una invisibilización de Asia Oriental. Este fenómeno como se verá más adelante se plasma en los resultados del cuestionario inicial del CIMA, en la que la mayor parte de los estudiantes dejaron las preguntas en blanco puesto que no poseían conocimientos previos sobre la historia de China. El impacto sobre el alumnado provocó que algunos de ellos subieran a su Instagram la diapositiva en cuestión tratando de hacerla viral entre sus seguidores.
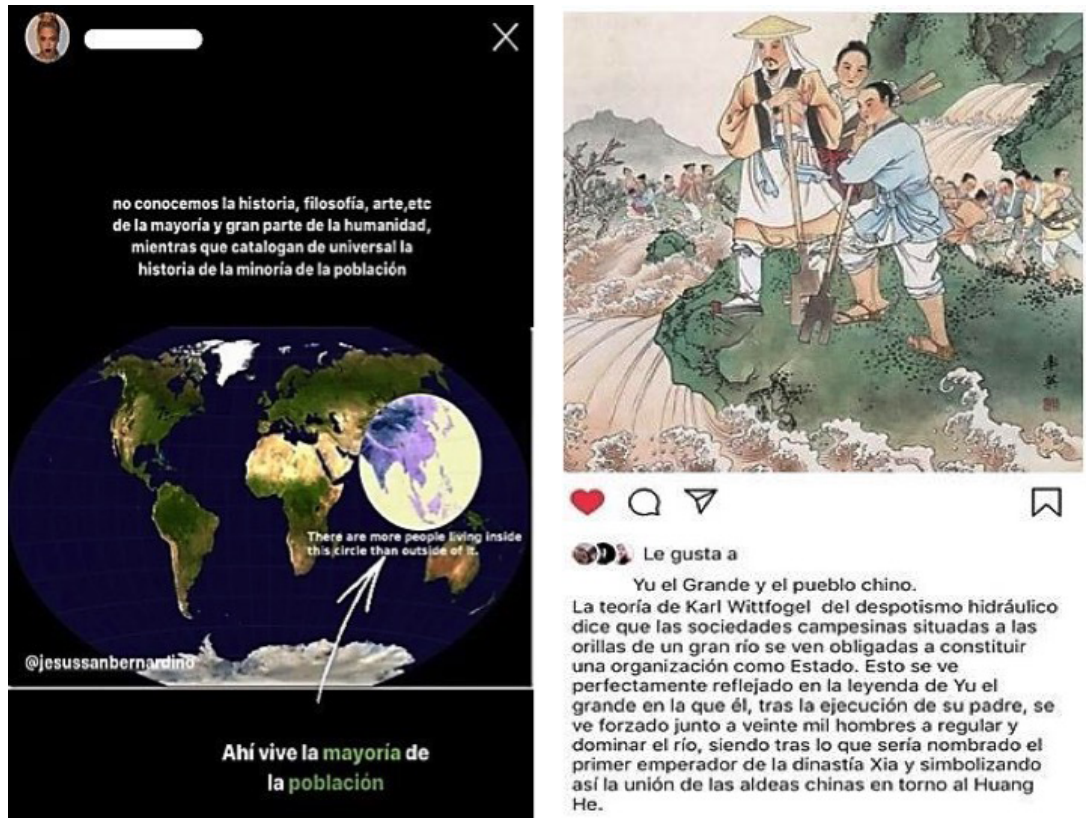

La teoria de Karl Wittfogel del despotismo hidráulico dice que las sociedades campesinas situadas a las orillas de un gran rio se ven obligadas a constituir una organización como Estado. Esto se ve perfectamente reflejado en la leyenda de Yu el perfectamente reflejado en la leyenda de Yu el
grande en la que él, tras la ejecución de su padre, se ve forzado junto a veinte mil hombres a regular $y$ dominar el río, siendo tras lo que sería nombrado el primer emperador de la dinastía Xia y simbolizando así la unión de las aldeas chinas en torno al Huang $\mathrm{He}$.

Figura 5: diapositivas usadas por estudiantes en sus redes sobre los contenidos de clase.

Para el tema 3 se repartió en el aula dos artículos extraídos de la Revista Instituto Confucio (un equivalente

Jornadas de Formación e Innovación Docente del Profesorado | № 2 (2019) 
para China a lo que sería el Instituto Cervantes en España: Huanghe (Río Amarillo): el río madre de la civilización china (Wang Wen, no 4, 2014: 30-39; enlace en línea: https://confuciomag.com/huanghe-rio-amarillo) y Yu el Grande y el control de la inundación mundial (Serer, no 44, 2017: 54-59; enlace en línea: https://confuciomag.com/yu-grande-xiainundacion-china). Para esta unidad temática reformulamos un poco el proyecto inicial y articulamos sesiones de trabajo en equipos de 4/5 estudiantes que debían contrastar y comparar la información entre ambos artículos. Se conformaron un total de 13 grupos que discutieron y trabajaron conjuntamente para rellenar el cuestionario con información comparada extraída de las dos publicaciones mediante lecturas comprensivas ("Dejar que hablen los libros" en Finkel, 2008: 47-74). Posteriormente se llevó a cabo una lluvia de ideas con las aportaciones expuestas por el representante de cada uno de los 13 grupos. Estas ideas fueron anotadas en la pizarra sucesivamente hasta conformar el mapa conceptual completo del grupo (figura 3) ("Dejar que hablen los estudiantes" en Finkel, 2008: 75102). El docente sugirió de qué manera ideas pertenecientes a apartados distintos podían interrelacionarse entre sí de esta forma los estudiantes pudieron visualizar las conexiones existentes entre diversas ideas claves, aparentemente no relacionadas. Finalmente el docente y algunos alumnos fotografiaron el resultado de la pizarra (figura 4) ("Vamos a indagar juntos" en Finkel, 2008: 103-129). Paralelamente algunos estudiantes subieron nuevamente a Instagram publicaciones sobre la figura de Yu el Grande, etiquetando la cuenta del docente. Destaca sorprendentemente que todos ellos se expresaron en el comentario en un perfecto castellano académico, usando además el lenguaje especifico de la disciplina o área de conocimiento (estudios de Asia Oriental).

La observación entre pares se realizó justo en esta sesión. Como resultado de esta actividad de innovación, la profa. Ángeles Castaño hizo transferencia de sus

Jornadas de Formación e Innovación Docente del Profesorado | № 2 (2019)

Esta obra se distribuye con la licencia Creative Commons 
observaciones e impresiones. Destacó el dinamismo de la clase, la capacidad de respuesta de los estudiantes, y la implicación de los grupos en elaborar respuestas con alta calidad de redacción y explicación. En relación a la actitud del docente, destacó la habilidad para mantenerlos activos y atentos haciéndolos partícipes de la dinámica de la clase. Si bien, se hace necesario también un mayor dominio de los tiempos en los primeros 15 minutos de clases, en los que los estudiantes tardaron un poco en comprender la secuencia de actividades y contenidos que tocaba abordar. En general valoramos muy positivamente la experiencia mutua de observación y su utilidad para mejorar la comunicación en el aula.

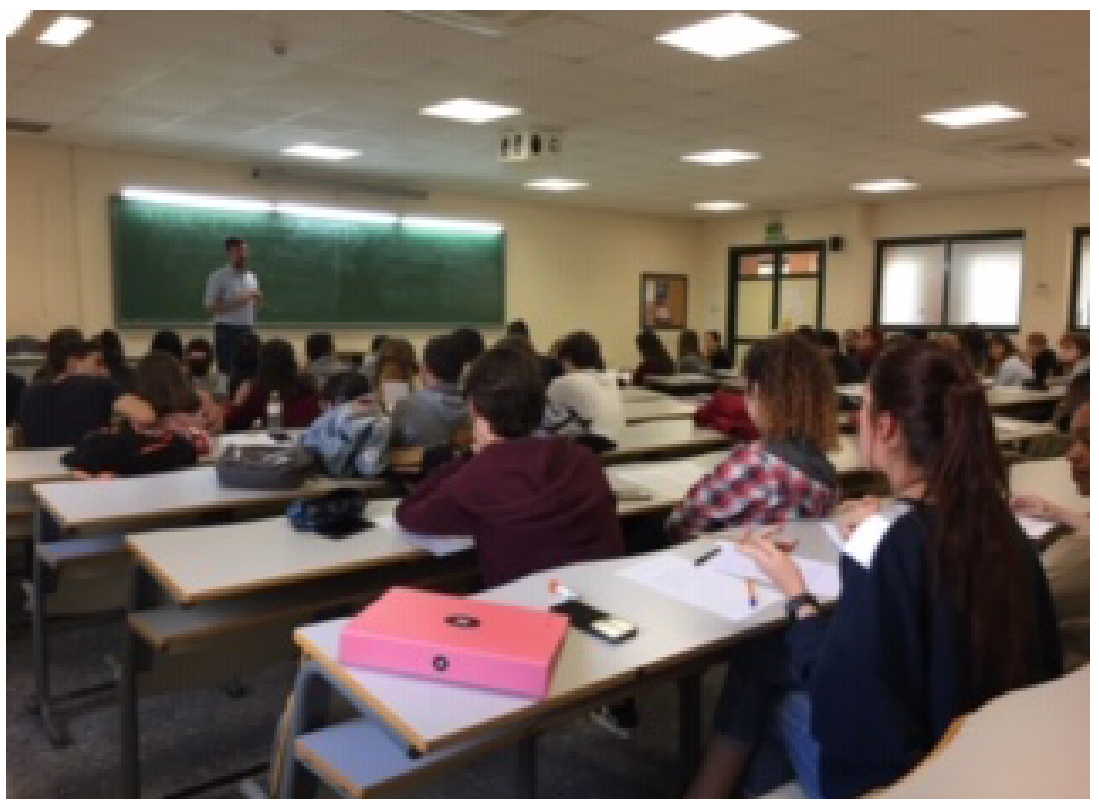

Figura 6: Observación entre pares de la enseñanza en el aula. Autora: Ángeles Castaño Madroñal.

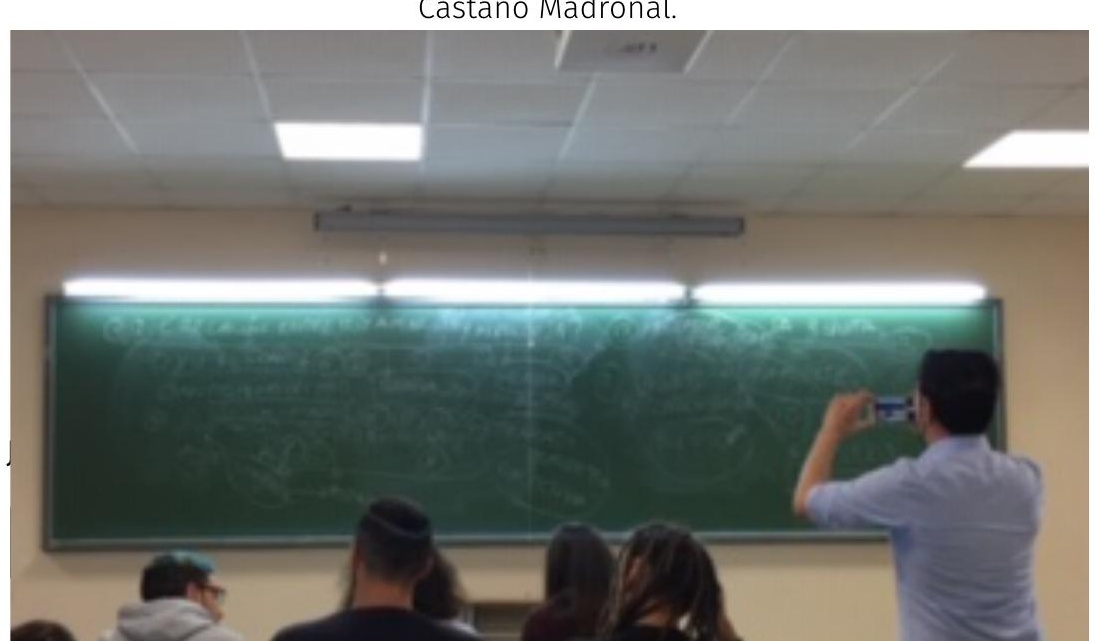


En relación con el tema 4 se distribuyó en la clase un cuestionario inicial de 5 preguntas para evaluar los conocimientos previos del alumno acerca de "La constitución de la historia China: Xia, Shang y Zhou" (donde se analizan cuestiones tan relevantes como el surgimiento de la escritura o la aparición del estado en China. Para la explicación debido a la premura del tiempo fue necesario acudir directamente a la información de contraste casi en clave de lección magistral, con inclusión de diapositivas y algunos videos. Tras esto se procedió a distribuir el mismo cuestionario con 5 preguntas, con el objeto de contrastar el nivel de aprendizaje de los alumnos como consecuencia de las estrategias de innovación docente aplicadas hasta el momento. De forma general, se confirma que los resultados fueron destacadamente positivos como se puede apreciar en los siguientes gráficos con sus escaleras de aprendizaje. Por razones de espacio, aquí solo abordaremos los resultados de la pregunta 1, la 2 y la 3 de los cuestionarios iniciales y finales, que resultan suficientemente elocuentes.

\section{Escaleras de aprendizaje: evaluación de los modelos iniciales y finales de los estudiantes}

- Pregunta 1: Cita las primeras tres dinastías de China
(50 respuestas en el cuestionario inicial y final)

Tabla 2. Resultados pregunta 1

\begin{tabular}{|l|c|c|c|c|}
\hline Clasificación & $\begin{array}{c}\text { Cuestionario } \\
\text { Inicial } \\
\text { (estudiantes) }\end{array}$ & $\begin{array}{c}\text { Cuestionario } \\
\text { inicial (\%) }\end{array}$ & $\begin{array}{c}\text { Cuestionario } \\
\text { final } \\
\text { (estudiantes) }\end{array}$ & $\begin{array}{c}\text { Cuestionario } \\
\text { final (\%) }\end{array}$ \\
\hline A & - & $0 \%$ & 44 & $88 \%$ \\
\hline B & 4 & - & 5 & $10 \%$ \\
\hline C & 10 & $20 \%$ & - & $0 \%$ \\
\hline D & 93 & $44 \%$ & - & $0 \%$ \\
\hline E & & & 1 & $2 \%$ \\
\hline
\end{tabular}

Jornadas de Formación e Innovación Docente del Profesorado | № 2 (2019) 
A: Escribe las tres palabras correctas; B: Escribe al menos dos palabras que son correctas; C: Escribe una única palabra que es correcta; D: Escribe una única palabra que además es incorrecta; E: No contesta.

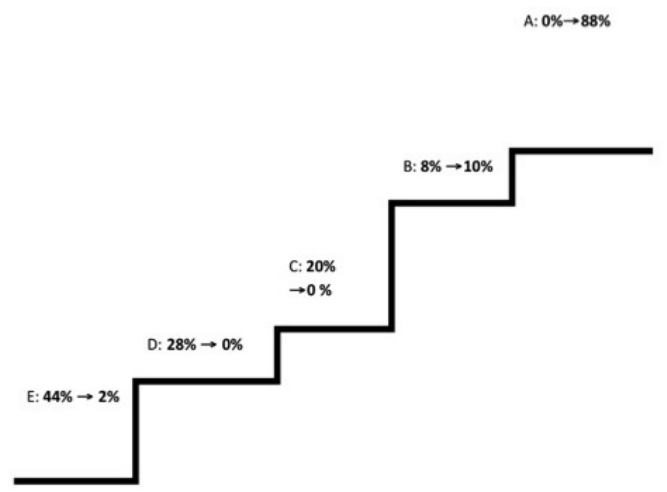

Figura 8. Escalera de aprendizaje de pregunta 1

Se observa claramente como la escalera E (no contesta) situada en un $44 \%$ inicialmente se modifica hasta un $2 \%$ final. En cambio en el otro puesto la escalera A en la que no había ningún alumno se llena hasta el $88 \%$ de la clase. El alumnado ha incrementado significativamente sus conocimientos hasta situarse en el nivel más alto A: un $88 \%$.

- Pregunta 2: ¿Cómo surge el Estado en China? (50 respuestas en el cuestionario inicial y final)

Tabla 3. Resultados de pregunta 2

\begin{tabular}{|l|c|c|c|c|}
\hline Clasificación & $\begin{array}{c}\text { Cuestionario } \\
\text { Inicial } \\
\text { (estudiantes) }\end{array}$ & $\begin{array}{c}\text { Cuestionario } \\
\text { inicial (\%) }\end{array}$ & $\begin{array}{c}\text { Cuestionario } \\
\text { final } \\
\text { (estudiantes) }\end{array}$ & $\begin{array}{c}\text { Cuestionario } \\
\text { final (\%) }\end{array}$ \\
\hline A & - & $0 \%$ & 19 & $38 \%$ \\
\hline B & - & $0 \%$ & 21 & $42 \%$ \\
\hline C & 2 & $4 \%$ & 2 & $4 \%$ \\
\hline D & 11 & $22 \%$ & 5 & $10 \%$ \\
\hline E & 40 & $74 \%$ & 3 & $6 \%$ \\
\hline
\end{tabular}

Jornadas de Formación e Innovación Docente del Profesorado | № 2 (2019)

Esta obra se distribuye con la licencia Creative Commons 
A: Identifica claramente el proceso de construcción estatal en China con diferentes y múltiples variables; B: Identifica un concepto más abstracto como la vertebración hidráulica y al menos dos factores; C: Identifica una figura concreta como el emperador o algún dato; D: Se atreve a hipotetizar de forma vaga; E: No contesta.

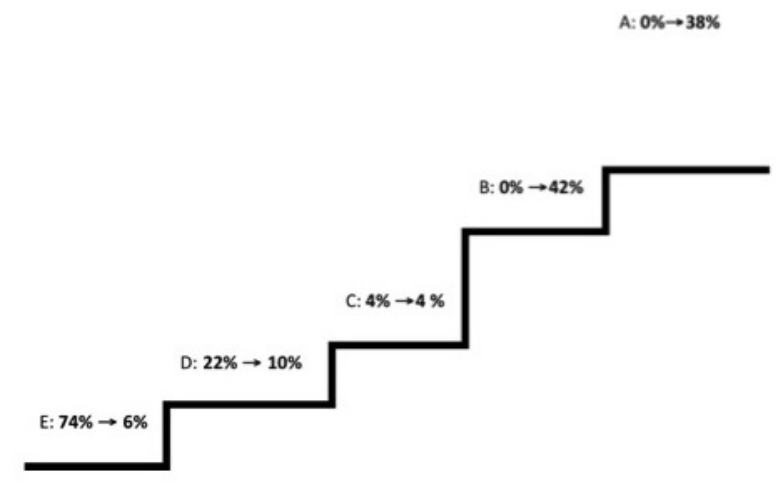

Figura 9. Escalera de aprendizaje de pregunta 2

En una pregunta de carácter mucho más complejo (¿Cómo surge el Estado en China?) los resultados también resultan marcadamente positivos. La gran mayoría de los alumnos estaba situada en el escalón E, no contesta. Sin embargo en el cuestionario final un $80 \%$ de los estudiantes han subido hasta el escalón más alto A y B que requieren razonamientos más complejos y con mayor integración de variables. Es de destacar que precisamente esos dos escalones estaban completamente vacíos en el cuestionario inicial con un $0 \%$ de estudiantes en ambos.

- Pregunta 3: ¿Cómo surge la escritura en China? (50 respuestas en el cuestionario inicial y final)

Jornadas de Formación e Innovación Docente del Profesorado | № 2 (2019)

Esta obra se distribuye con la licencia Creative Commons 
Tabla 4. Resultados de pregunta 3

\begin{tabular}{|l|c|c|c|c|}
\hline Clasificación & $\begin{array}{c}\text { Cuestionario } \\
\text { Inicial } \\
\text { (estudiantes) }\end{array}$ & $\begin{array}{c}\text { Cuestionario } \\
\text { inicial (\%) }\end{array}$ & $\begin{array}{c}\text { Cuestionario } \\
\text { final } \\
\text { (estudiantes) }\end{array}$ & $\begin{array}{c}\text { Cuestionario } \\
\text { final (\%) }\end{array}$ \\
\hline A & - & $0 \%$ & 15 & $30 \%$ \\
\hline B & 4 & $8 \%$ & 23 & $46 \%$ \\
\hline C & 12 & $24 \%$ & 6 & $12 \%$ \\
\hline D & 25 & $50 \%$ & 4 & $8 \%$ \\
\hline E & 9 & $18 \%$ & 2 & $4 \%$ \\
\hline
\end{tabular}

A: Identifica claramente el proceso de surgimiento de la escritura con más de dos variables; B: Identifica conceptos más abstractos como la escapulimancia; C: Identifica al menos un factor concreto en el proceso como la pictografia; D: Se atreve a hipotetizar de forma vaga; E: No contesta.

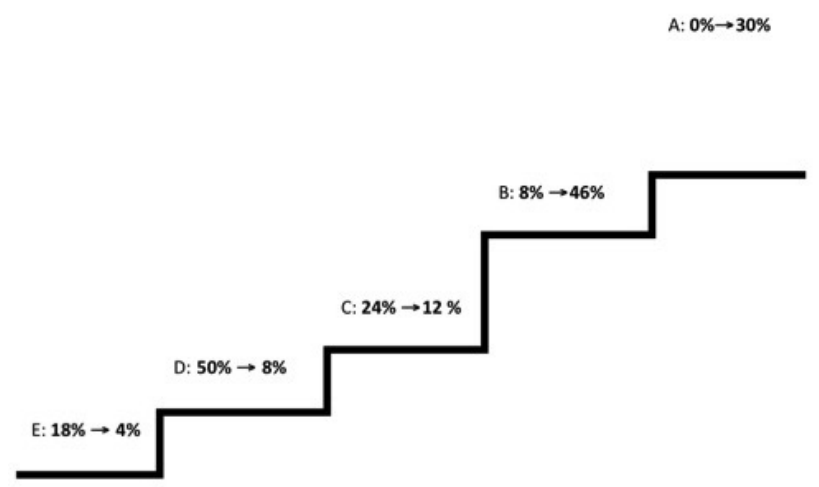

Figura 10. Escalera de aprendizaje de pregunta 3

Esta escalera de aprendizaje acerca del surgimiento de la escritura en China se distingue claramente de las dos anteriores dado que ningún alumno dejó sin responder ninguna de las preguntas salvo en el escalón A. En los cuatro restantes escalones los alumnos oscilan entre el $8 \%$ del escalón B y el $50 \%$ del escalón D. Destaca por tanto el gran incremento de respuestas de mayor nivel tras la

Jornadas de Formación e Innovación Docente del Profesorado | № 2 (2019)

Esta obra se distribuye con la licencia Creative Commons 
aplicación de la estrategia docente con un 76\% copando los escalones A y B. Destaca especialmente la gran subida experimentada en el nivel más alto A: se pasa de un $0 \%$ de la clase a un $30 \%$ de la clase capaz de entender un proceso tan complejo y con tantas variables como la formación del Estado en China.

El tema 5 fue impartido mediante información de contraste tanto teórica como práctica alejándonos de la tradicional clase magistral, debido a la gran participación de los alumnos, debido a su actitud mucho más proactiva a estas alturas del cuatrimestre.

Este fue el último tema impartido en el tiempo concebido a los tres primeros créditos de la asignatura: debido al problema de falta de tiempo y a la gran intervención de los 65 estudiantes y sus correspondientes 13 grupos resultó imposible llegar a culminar la previsión de nuestro cronograma temático. De hecho, un grupo de alumnos en el cuestionario final de evaluación de la materia impartida señala taxativamente que tres créditos son muy escasos para analizar más de 3.000 mil años de historia de China, Japón y Corea. Como docente estimo también que la principal dificultad encontrada radica en el escaso tiempo para explicar una materia tan extensa que abarca tantos miles de años. La gestión de los tiempos resulta muy dificil además en un grupo numeroso que alcanza casi los 70 alumnos.

\section{Autoevaluación de la dinámica de la clase.}

\section{Autoevaluación del alumnado}

La intervención de los 13 grupos (que integrados por 4/5 alumnos) también supuso un gran gasto del poco tiempo disponible al que hay que sumar el tiempo

Jornadas de Formación e Innovación Docente del Profesorado | № 2 (2019)

Esta obra se distribuye con la licencia Creative Commons 
invertido en la puesta en común y lluvia de ideas para extraer las conclusiones en el aula. Como contrapartida positiva podemos destacar la alta participación y actitud proactiva de un alumnado tan vocacional y motivado como el que estudia este grado. Esta cuestión se manifestó no solo a través de la observación en el aula sino también a través de la utilización de Instagram por parte de alumnado para exponer contenidos impartidos en la asignatura; a los casos ya citados anteriores podemos añadir las subidas a dicha red social de un acontecimiento visto en clase: la invención del papel por Cai Lun consejero de la dinastía Han en el año 105 a.C. (figura 7). Estos y otros descubrimientos chinos suscitaron un destacado interés claramente palpable en el aula.

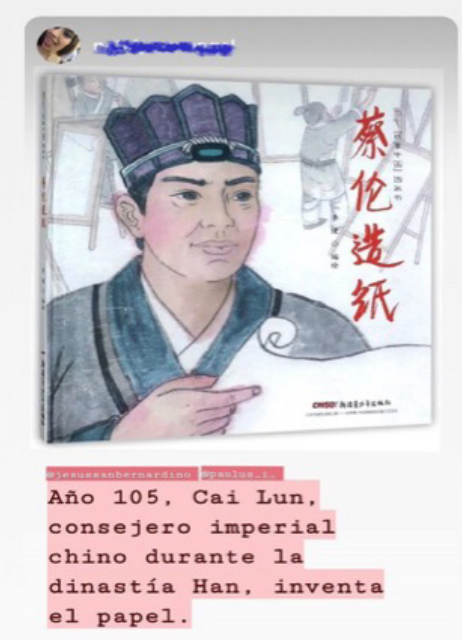

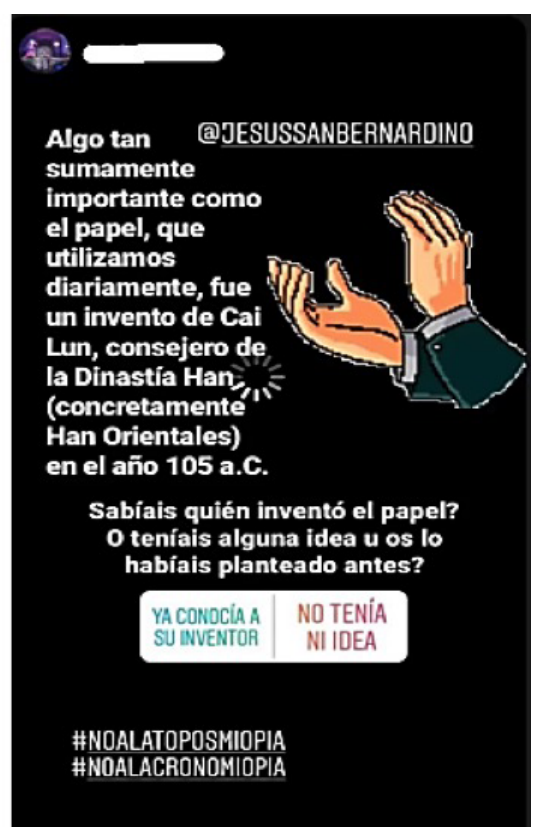

Figura 11. Imágenes circuladas en las redes digitales sobre contenidos de la asignatura.

Se realizó un cuestionario de autoevaluación final de la asignatura impartida, una vez finalizado el proyecto de innovación docente, el último día del curso a mediados de noviembre (Bain: 2007: 167-191). Estas son las cuatro

Jornadas de Formación e Innovación Docente del Profesorado | № 2 (2019)

Esta obra se distribuye con la licencia Creative Commons Reconocimiento-NoComercial-SinObraDerivada 
preguntas que se formularon y a la que contestaron 54 alumnos.

1. Destaca dos ideas interesantes que consideres que has aprendido.

2. Destaca dos ideas importantes que consideres que has aprendido.

3. ¿Por qué crees que ha ocurrido este aprendizaje?

4. Valoración final.

Todos los estudiantes expresaron sin excepción dos ideas que les habían interesado y otras dos que les parecían importantes para el conjunto de la asignatura. Entre ellas aparecen de forma notoria un gran número de conceptos como "eurocentrismo", "presentismo", "orientalismo", "orientalismo inverso", "cronomiopía", "topomiopía", "prejuicios" y "estereotipos" entre muchos otros. Otro grupo de estudiantes además destaco su interés por mitos ajenos a la cultura grecorromana y judeocristiana como por ejemplo el mito del gran Yu (que es también un mito del diluvio universal). Por último, se repite abundantemente el razonamiento de que en realidad todo les había parecido interesante e importante porque tenían un gran desconocimiento previo sobre las realidades históricas y culturales de la China antigua.

En relación con las preguntas 3 y 4 que valoran el proceso de aprendizaje prácticamente todos contestaron que éste había sido posible por dos razones básicas: el propio interés del estudiante y la forma de impartirlo. Destacamos algunas de las respuestas con los pseudónimos usados por los alumnos:

Jornadas de Formación e Innovación Docente del Profesorado | № 2 (2019)

Esta obra se distribuye con la licencia Creative Commons 


\section{Tabla 5. Evaluaciones destacadas de los estudiantes}

\begin{tabular}{|c|c|}
\hline "Lonso" & por su forma de dar clase y mi puesta de interés. \\
\hline "Inu" & $\begin{array}{l}\text { Porque me resultó interesante el contenido y también la forma de } \\
\text { impartirlo. El hacer que en pequeños grupos tengamos la capacidad } \\
\text { para investigar un poco hace que se queden mejor las cosas. }\end{array}$ \\
\hline “ji" & $\begin{array}{l}\text { Aunque no era la parte de la historia que más me interesaba he } \\
\text { acabado interesándome por esta etapa de la historia de China gracias } \\
\text { a las dinámicas originales que ha propuesto el profesor }\end{array}$ \\
\hline “No" & $\begin{array}{l}\text { Es una asignatura muy interesante pero que daba para mucho más, la } \\
\text { falta de tiempo ha hecho que no se profundice tanto como me habría } \\
\text { gustado. Pero es muy buena asignatura, con un profesor que se nota } \\
\text { que ama su trabajo y nos trasmite su pasión. }\end{array}$ \\
\hline "Huang Fu" & $\begin{array}{l}\text { En general está a sido una muy buena asignatura con métodos } \\
\text { docentes alternativos que funcionan y donde ha habido una } \\
\text { muy buena exposición (aunque necesariamente sintetizada) de } \\
\text { conocimientos. Muchas gracias. }\end{array}$ \\
\hline “Luna” & $\begin{array}{l}\text { Clases activas e interesantes que te permiten un buen aprendizaje } \\
\text { de la asignatura. Buena comunicación profesor-alumno y material } \\
\text { docente adecuado y útil para seguir de forma efectiva las clases. Muy } \\
\text { buen clima de clase basado en la motivación constante que permite } \\
\text { mantener el entusiasmo por esta asignatura y el grado en general. }\end{array}$ \\
\hline "Isabel" & $\begin{array}{l}\text { (...) Además ha utilizado diferentes métodos docentes que me han } \\
\text { facilitado el aprendizaje. }\end{array}$ \\
\hline "Praun" & $\begin{array}{l}\text { La asignatura está bien estructurada, las explicaciones son claras y } \\
\text { no resulta especialmente complicado comprender el temario. Valoró } \\
\text { positivamente que el profesor invierta su tiempo en responder todas } \\
\text { nuestras dudas. Sin embargo creo que se empezó a profundizar } \\
\text { demasiado tarde en la materia y que el profesor se tomó demasiadas } \\
\text { clases como preámbulo. }\end{array}$ \\
\hline "Cori" & $\begin{array}{l}\text { Sinceramente, historia nunca llegó a ser una de mis asignaturas } \\
\text { favoritas (...) Y en esta asignatura, con este profesor, he quedado } \\
\text { totalmente satisfecho, tanto por los datos aportados, como el soporte } \\
\text { visual y la pasión que derrochaba en las explicaciones (llegando a } \\
\text { enfadarse sutilmente incluso cuando hablábamos de temas injustos } \\
\text { o el colonialismo europeo. Me encantó, } 10 \text { de } 10\end{array}$ \\
\hline "Aki" & $\begin{array}{l}\text { Me ha resultado muy interesante el profesor ha sabido cómo } \\
\text { hacernos sentir integrados en la clase y mediante el soporte } \\
\text { audiovisual, se han vuelto clases más amenas y llevaderas. }\end{array}$ \\
\hline
\end{tabular}

Aunque un número importante de estudiantes valora positivamente los conceptos analizados en la parte introductoria de la asignatura y los métodos, otros estudiantes,

Jornadas de Formación e Innovación Docente del Profesorado | № 2 (2019)

Esta obra se distribuye con la licencia Creative Commons 
como "Praun" resultan más críticos con la gestión del tiempo empleada en dicha parte.

En algunos casos se identifica la existencia de contenidos actitudinales. Véase por ejemplo la apreciación de "Cori" sobre el enfado sutil del profesor ante realidades consideradas injustas...

\section{Autoevaluación del docente}

La experiencia del CIMA realizado nos ha resultado altamente positiva. Como conclusión de nuestra propia observación mantendremos el método vertebrado mediante el Aprendizaje en base a la resolución de problemas por sus múltiples beneficios (Porlan: 73-91): 1. La implicación del alumnado desde el inicio al ser retado por las preguntas; 2 . El favorecimiento de actitudes proactivas, al verse involucrados de algún modo en un proceso indagador; 3. Los resultados en cuanto a retención y aprehensión de contenidos por parte de los discentes. Igualmente mantendremos la estrategia docente de trabajos en grupo de 4/5 alumnos para que discutan y resuelvan el problema planteado: ello les obliga a razonar, argumentar, informarse, dialogar, negociar y acordar con los compañeros al objeto de formular una respuesta de consenso.

En relación al mapa de contenidos procuraremos en el futuro ajustarlo al tiempo real en el aula a pesar del obstáculo que supone impartir una materia tan extensa en tan poco espacio de tiempo (3 créditos). Subrayamos que ésta es una cuestión en la que inciden intensamente los propios educandos en la autoevaluación final. Ajustaremos en la medida de lo posible el cronograma en función de los contenidos. Para aligerar la inversión en tiempo seleccionaremos en los trabajos en grupo con lectura sólo a una parte de los grupos dado que la intervención de los 13 grupos consume un tiempo excesivo. Otra posible solución

Jornadas de Formación e Innovación Docente del Profesorado | № 2 (2019)

Esta obra se distribuye con la licencia Creative Commons 
sería que los 13 grupos no contestaran a todas las preguntas de cuestionario vinculado a la lectura sino solo a una o dos de ellas. Estos constituyen en líneas generales los principios didácticos (Porlán 2017: 93-118) que pretendemos incorporar a toda la práctica docente habitual y que deseamos mantener en el futuro.

Otra innovación de interés tanto para los docentes como para la percepción de los propios estudiantes sobre la implicación de los profesores en la mejora docente, es incentivar la observación entre pares, incrementando una observación más larga en una actividad clave de la secuencia que diseñemos el próximo curso.

Jornadas de Formación e Innovación Docente del Profesorado | № 2 (2019)

Esta obra se distribuye con la licencia Creative Commons 


\section{Referencias bibliográficas}

Bain, K. (2007). Lo que hacen los mejores profesores universitarios. Valencia: Publicaciones de la Universidad de Valencia.

Castaño, A. (2018). Aprendizaje en Antropología de la Comunicación a través de proyecto: los secretos de "Assasin's Creed IV:Black Flag" y "FIFA18" descubiertos por estudiantes en Jornadas de Formación e Innovación Docente del Profesorado, no 1 (2018) 1811-1832. D.O.I.: http://dx.doi.org/10.12795//DDU.2018.i01.102

Finkel, D. (2008) Dar clase con la boca cerrada. Valencia: Publicaciones de la Universidad de Valencia.

Ita Tsai (2019) (ed.) Chino, Capuchino. Cómo los estereotipos afectan a los españoles [enlace en línea: https:/ / www.youtube.com/watch?v=AmosZxePEZo]

Porlán Ariza, R. (coord.) (2017). Enseñanza Universitaria. Cómo mejorarla. Madrid: Ediciones Morata.

Serrer Martínez (2017) Yu el Grande y el control de la inundación mundial. Revista Instituto Confucio no 44, 54-59 [enlace en línea: https://confuciomag.com/ yu-grande-xia-inundacion-china]

Wang Wen (2104) Huanghe (Río Amarillo): el río madre de la civilización china. Revista Instituto Confucio, no 4, 30-39; [enlace en línea: https://confuciomag.com/ huanghe-rio-amarillo]

Jornadas de Formación e Innovación Docente del Profesorado | № 2 (2019)

Esta obra se distribuye con la licencia Creative Commons 